\title{
Learning Curves for Solid Oxide Fuel Cells
}

R. Rivera-Tinoco, K. Schoots, B.C.C. van der Zwaan

This document appeared in

Detlef Stolten, Thomas Grube (Eds.):

18th World Hydrogen Energy Conference 2010 - WHEC 2010

Parallel Sessions Book 1: Fuel Cell Basics / Fuel Infrastructures

Proceedings of the WHEC, May 16.-21. 2010, Essen

Schriften des Forschungszentrums Jülich / Energy \& Environment, Vol. 78-1

Institute of Energy Research - Fuel Cells (IEF-3)

Forschungszentrum Jülich $\mathrm{GmbH}$, Zentralbibliothek, Verlag, 2010

ISBN: 978-3-89336-651-4 


\title{
Learning Curves for Solid Oxide Fuel Cells
}

\author{
R. Rivera-Tinoco, K. Schoots, Energy research Centre of the Netherlands, Policy \\ Studies, The Netherlands
}

B.C.C. van der Zwaan, Energy research Centre of the Netherlands, Policy Studies; Columbia University, Lenfest Center for Sustainable Energy, The Earth Institute, New York City, NY, USA

\begin{abstract}
We present learning curves for solid oxide fuel cells (SOFCs) and combined heat and power (CHP) SOFC systems with an electric capacity between 1 and $250 \mathrm{~kW}$. On the basis of the cost breakdown of production cost data from fuel cell manufacturers, we developed a bottom-up model that allows for determining overall manufacturing costs from their respective cost components, among which material, energy, labor, and capital charges. The results obtained from our model prove to deviate by at most $13 \%$ from total cost figures quoted in the literature. For the early pilot stage of development, we find for SOFC manufacturing a learning rate between $14 \%$ and $17 \%$, and for total SOFC system fabrication between $16 \%$ and $19 \%$. We argue that the corresponding cost reductions result largely from learning-by-searching effects (R\&D) rather than learning-by-doing. When considering a longer time frame that includes the early commercial production stage, we find learning rates between $14 \%$ and $39 \%$, which represent a mix of phenomena such as learning-by-doing, learning-by-searching, economies-of-scale and automation.
\end{abstract}

Keywords: SOFC, learning-by-doing, economies-of-scale, automation

\section{Introduction}

Interest in power generation with solid oxide fuel cells (SOFCs), as well as R\&D dedicated to this type of technology, has considerably increased over the past few years. Among the reasons are their high efficiency relative to conventional gas and coal based power units: even in comparison to for instance an integrated gasification combined cycle (IGCC) plant their electric efficiency is typically more than $10 \%$ higher [1]. Another explanation for the increased attention for SOFCs is the possibility of effectively recovering their exhaust heat, given the high temperatures under which they operate. As with other fuel cell systems, a combined heat and power (CHP) SOFC system consists of a stack of SOFCs and a balanceof-plant (BoP). The electrochemical reaction between oxygen and the fuel - such as hydrogen, methane or (a mix of) other hydrocarbon gases - takes place in the stack of fuel cells. The BoP supports the stack, drives the fuel through the fuel cells and can recover energy from the high-temperature exhaust gas.

In spite of their high electric efficiency and ensuing economic benefits, the fabrication costs of SOFC systems, and hence their purchase prices, are still significantly higher than strategically adopted target values. As a result, the cost of electricity generation with SOFCs are today well above those of most conventional alternatives. The development of SOFCs, however, is only in the pilot stage and has not yet reached full commercial production. 
Hence, progressively significant cost reductions are expected for the future when the technology transits through the various stages of maturation.

The learning curve methodology allows for estimating the cost prospects of innovative technology and allows for determining the competitive breakeven point with respect to existing technology. The developed learning curves may apply to a large range of different types of technologies and serve company strategic purposes and as a tool for public policy making. For the latter, we found information notably of energy-related technologies [2-5]. The rapidity of learning is usually expressed by the learning rate, a measure for the relative cost reduction of a good with every doubling of produced or installed capacity. A learning curve expresses graphically the cost decrease of a technology and is usually represented by a power law (see equation 1). When cost and cumulative capacity data are plotted on a double-logarithmic scale, the power law of a learning curve becomes a downward sloping straight line. The slope of this line is called the learning index $(\alpha)$ [6-7], which can be reformulated as the learning rate (Ir) (see equation 2).

$$
\begin{aligned}
& C_{t}=C_{0}\left(\frac{P_{t}}{P_{0}}\right)^{-\alpha} \\
& \operatorname{lr}=1-2^{-\alpha}
\end{aligned}
$$

Schoots et al. [8] present an extensive analysis of learning phenomena for fuel cells and the present work aims to complement this recent fuel cell learning curve study, since so far no learning rates have been reported - or have been determined - for SOFCs. In our fuel cells case, the variables in equation 1 are the costs of SOFCs at time $t\left(c_{t}\right)$, the costs of SOFCs in the first batch of production (the time of which is referred to as $t=0)\left(c_{0}\right)$, the cumulated production of SOFCs at time $t\left(P_{t}\right)$, and the number of SOFCs in the first fabrication batch (hence at $t=0)\left(P_{0}\right)$. We express values of $P$ either in number of SOFCs (typically for fuel cells) or in terms of their capacity (hence in $\mathrm{kW}$, for example when referring to SOFC systems).

\section{Cost Requirements for SOFCs}

In the current pre-commercial production phase, planar and tubular geometries of SOFCs dominate triangular and other shapes. For all these geometries, individual fuel cells are assembled in stacks that are subsequently integrated with the BoP. An individual fuel cell consists of a multilayer device including the anode, electrolyte, cathode, and interconnects. For today's SOFC manufacture, the first three components are made of state-of-the-art ceramics, such as respectively Nickel Oxide - Yttria Stabilized Zirconia (NiO-YSZ), YSZ and Lanthanum Strontium Manganite (LSM). Interconnects are fabricated usually of high performance stainless steel alloys [9-12]. Below we will mostly investigate planar SOFCs, because data for this type are more abundant than for tubular SOFCs. An analysis of the manufacturing sequence and cost components of SOFC production, as described in the following sections, serves to estimate total fuel cell and system fabrication costs. The latter constitute the basis for our attempt to determine a learning curve for SOFCs. 


\section{Total costs}

The planar SOFC are produced according to a specific sequence of steps and techniques that depend on (and determine) the manufacturing material, processing speed, production yield, and fuel cell width [13-15]. For our study we assess the most commonly used method for multilayer ceramics manufacturing, which is the tape-casting of anode and screen-printing of electrolyte and cathode. After the cutting process elementary fuel cells are formed by adding shaped interconnects to the multilayered ceramic units. A series of individual fuel cells are piled together to become an SOFC stack.

Most intricacies of SOFC manufacturing techniques and materials are well documented in the literature. However, while cost components related to the use of materials and energy are usually fairly well known, little information is often available on contributions from notably labor and capital charges. This implies that total manufacturing cost values quoted in public sources possess a high degree of heterogeneity. This complicates attempts to observe learning phenomena, and renders difficult efforts to calculate accurately learning rates. In order to determine the presence (or absence) of learning-by-doing, and develop learning curves, we have greatly endeavored to subtract heterogeneity from our data set as much as possible. For this purpose, we developed a detailed bottom-up model in which we distinguish between the four main cost components that contribute to the overall SOFC production process:

- Material costs. Total annual material costs are estimated accounting volume and price of materials purchased per year by a manufacturing facility.

- Energy costs. We assume that annual energy expenses results from the total fuel cell capacity produced by a facility per year, the energy requirements per unit of capacity [15] and the energy costs.

- Labor costs $\left(C_{l a b}\right)$. Collected data show that, when no process automation techniques are implemented, the work directly related to manufacturing and stack assembling is performed by typically five individuals full-time employed when an annual volume of 25000 fuel cells is produced [16-17]. We assume that $C_{l a b}$ is proportional to the gross Average Employment Income $(A E I)$ in the country of SOFC manufacturing under consideration [18] and that, with no automation, the number of individuals employed in the plant increases linearly, $\beta=1.0$, with the fuel cell production scale, and when process becomes automated $0.2 \leq \beta$ < 1.0: $C_{l a b}=A E I\left(N_{f c} \frac{5}{25000}\right)^{\beta}$

- Capital charges. Two main types of capital charges can be distinguished as investment requirements for the construction of a fuel cell production facility: equipment costs $\left(C_{e q}\right)$ and terrain- and building costs $\left(C_{t r}\right)$. Both represent figures for total capital costs per annum $\left(C_{c a p}\right)$ as they are transformed from total investment values into annual capital costs through the annuities relationship for capital refunding: $C_{c a p}=\left(C_{e q}\right)\left[\frac{r}{(1+r)^{-T}-1}\right]+\left(C_{t r}\right)\left[\frac{r}{(1+r)^{-T}-1}\right]$ in which $r$ is the interest rate (which we suppose to be $8 \%$ ) and $T$ the period of loan amortization (for which we assume a time frame of 10 years). 
From a survey of the literature, we assume in our model that the total level of equipment costs varies linearly with the expenses related to the acquisition of furnaces, for which we suppose a dominating constant average contribution of $50 \%$ [16-17]. Aware of the latter, the model allows for estimating fuel cell manufacturing cost values under several assumptions of economies-of-scale on furnace prices.

\section{Learning Curves for SOFCs}

We present in this section the learning curve study for production cost of SOFCs. Available yield and cost data derives from R\&D, pilot and early commercial stages for the major fuel cell manufacturers. With exemption of CFCL, because of its business plan statements, this study deals with learning phenomena for both at each stage and total lifetime of HC Starck, Versa and Topsoe facilities. As means of a tool, our cost model enables to separately study cost reductions driven by non-learning phenomena, as well as rendering cost data homogeneous, and estimating additional cost values.

\subsection{Improving production yield}

An important facet of the produced capacity figure is the production yield of fuel cells, that is, what is the number of SOFCs successfully manufactured per production bulk. Failure on fuel cell production takes place mainly during the sintering step, followed by the multilayer production and handling steps [13]. Our analysis show that effort on R\&D and experience acquired results on $11 \%$ decrease on failure rate every doubling on cumulative capacity of fuel cells. Once early commercial production of SOFCs starts, a minimal yield rate of $80 \%$ is observed frequently.

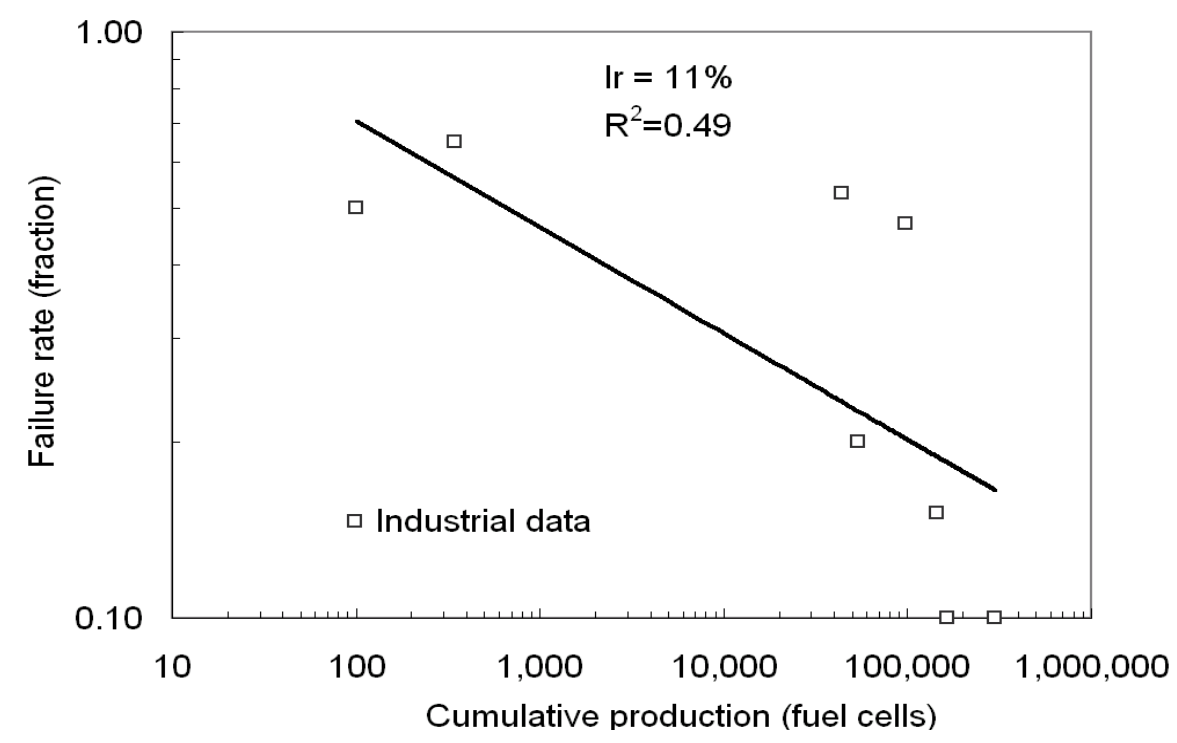

Figure 1: Learning curve for the failure rate of fuel cell production processes. Data from VERSA, Topsoe, HC Starck. [19-22]. 


\subsection{Reducing manufacturing costs}

Commencing this section with the major European manufacturer (HC Starck), we gather production cost values from R\&D, pilot and early commercial production stages in the same plot (see figure 2). We include cost data and modeled cost values. Cost reduction obtained through automation and economies-of-scale are not studied in this step of the analysis.

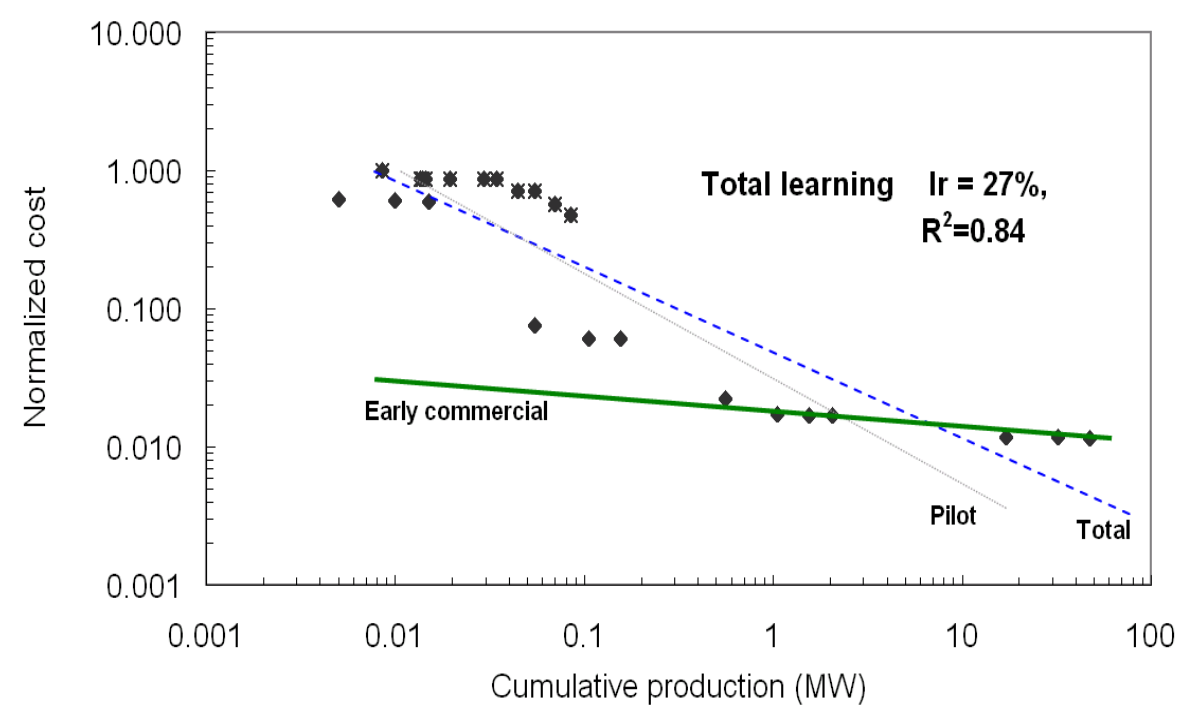

Figure 2: Learning curves for SOFC manufacturing. Data from HC Starck [16] and our model.

We estimate the learning rate value for R\&D stage at $16 \%$ and for which material and labor costs remain high and are not affected for the volume of fuel cells produced. During the pilot stage, we observe that the learning rate every doubling of cumulative capacity is up to $42 \%$. However, we estimated fuel cell production costs with our model subtracting the influence of economies-of-scale from material costs. Whether the purchase volume of powders, we assumed constant values for material costs. Learning rate results on a value of $27 \%$ and we suppose represents mainly pure learning-by-doing. Early commercial stage faces constrains against labor and capital costs, rather than material costs. The learning rate value is estimated at $5 \%$ and we suppose that learning-by-doing phenomena are mainly represented. Accounting the relevant impact of labor and capital costs since the early commercial production stage is reached we studied further potential cost reductions driven by automation. Economies-of-scale related to material purchase volume and equipment investments are simultaneously considered. The learning rate reaches values from $35 \%$ to $39 \%$ for slightly to highly automation respectively. 


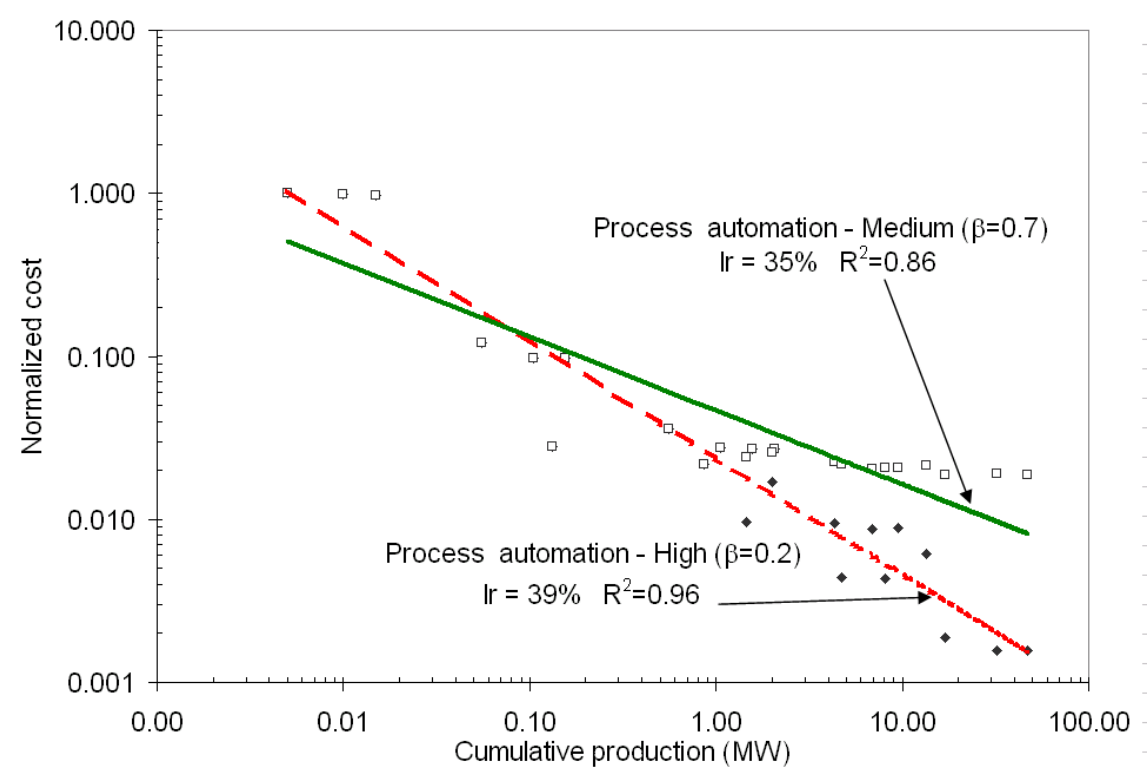

Figure 3: Modeled cost values for SOFC production under assumptions for automation and economies-of-scale effects. Data from our model and from HC Starck [16].

As our model is based on production capacity data, instead of current production capacity, and accounting that $\mathrm{HC}$ Starck has the highest capacity among the major fuel cell producers, we performed the sensitivity study of the impact of pilot and early commercial production capacity on cost estimations. Cost data available and estimated, only for the R\&D stage, were straightly retained as they correspond to accurate values of produced fuel cells. For further production stages, we supposed a $50 \%$ load factor of the HC Starck facility. The Ir results on $30 \%$ for medium automated facility $(\beta=0.7)$ instead of $35 \%$ estimated with $100 \%$ load factor. This enables to estimate a maximal impact on $\mathrm{Ir}$ values of $5 \%$ derived from uncertainties in manufacturers load factor.

Accounting facility capacity important differences, cost data from VERSA and Topsoe facilities are studied separately. Both facilities present a capacity equivalent to a R\&D - semi pilot stage. Estimated fuel cell production costs deviate at most $13 \%$ of literature data. Learning rate values are found between $14 \%$ and $17 \%$. Learning rate values from HC Starck, Versa, and Topsoe confirm that mainly learning-by-searching phenomena enable to reduce production costs by around $15 \%$. Based on the fact that a confirmed value for learning curves is found at R\&D and pilot production capacities, we will retain the costs and capacity data in order to go further with our learning curve analysis for SOFC systems.

\section{$4 \quad$ Learning Curves for SOFC Systems}

\subsection{BoP costs}

Material, energy, labor, and capital costs are included in the modeling of BoP manufacturing cost under similar assumptions than fuel cell production. The latter assumes that material and energy cost values derive from the required elements and their needed quantities to build up the BoP. As information related to labor costs (individuals needed) to produce and assemble the BoP is highly scarce and heterogeneous, the number of individuals is assumed 
to be equal to the one for SOFCs manufacture. The total SOFC system labor cost would then become twice the value of fuel cell labor cost. For capital costs, we assume that they can be neglected. Indeed, the means required for these cost components are relatively small in comparison to the other contributions to overall costs.

\subsection{System learning}

Estimated cost values for $5 \mathrm{~kW}$ SOFC systems show that BoP contribution to total system manufacturing cost represents $64 \%$. The latter fits with data provided by the consulting firm Arthur D. Little Inc. [23]. For different SOFC system capacities, the number of fuel cells contained in the stacks varies linearly with the requested power output. However, BoP would present a non-linear variation resulting on variable cost contribution, such as presented by Schoots et al. for PEMFC systems [8]. As the value of $64 \%$ is the only data point available for BoP contribution to SOFC system cost, we assumed that it would become the reference point for scaling contribution values for different SOFC systems presenting various power output values. The former is modeled under assumptions for an analogical behavior between PEMFC and SOFC BoP contribution to the system cost. The plot of modeled system costs based on R\&D and pilot production capacities and data available derive on learning rate values for 1 to $250 \mathrm{~kW}$ SOFC systems between $17 \%$ and 19\% (figure 4). The refunding of capital charges for both fuel cell and BoP side are not included in the costs plotted, but they would importantly increase the system cost depending on economic parameters used to discount investments.

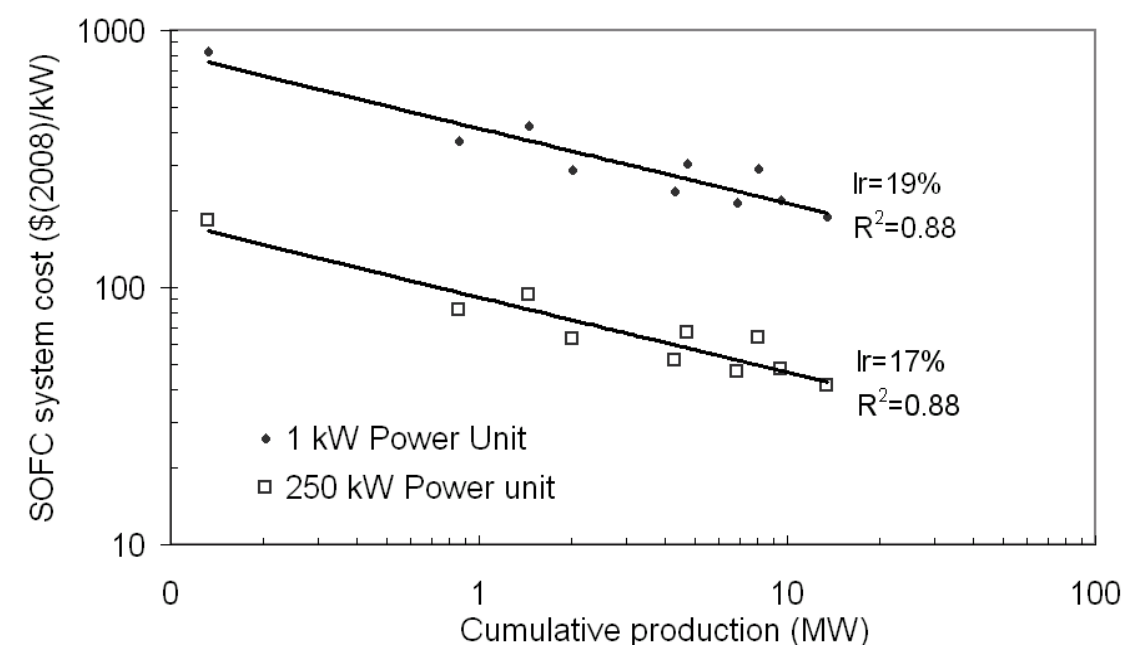

Figure 4: Learning curve for planar SOFC systems for 1 and $250 \mathrm{~kW}$ (electric power output). Modeled data and obtained from [23].

\section{Conclusion}

The learning curves for SOFCs and their systems presented in this paper are derived from modeled manufacturing costs as well as manufacturer data from the open literature. For the R\&D and pilot stage of planar SOFCs, we obtained learning rates ranging from $14 \%$ to $17 \%$. For the stages beyond, i.e. the early commercial phase, we modeled manufacturing cost 
data and applied corrections in order to eliminate effects from economies-of-scale and automation. These data in combination with production capacity figures from HC Starck formed the basis of our learning-by-doing analysis. We found a learning curve characterized by a learning rate of $27 \pm 15 \%$. If phenomena of automation and economies-of-scale, as additional major drivers of cost reductions, had been taken into account, we would have obtained a learning rate of $39 \%$. We point out that such a high rate is unsustainable. At any rate, in this and other papers, we demonstrate that the phenomenon of learning tends to decay, and gradually phase out towards zero. Based on real and modeled cost data from facilities run by VERSA and Topsoe, we find learning rates between $17 \%$ and $19 \%$ for SOFC systems with an electric output between $1 \mathrm{~kW}$ and $250 \mathrm{~kW}$. These values correspond well with observed learning rates determined for a wide range of other energy technologies. Like with planar SOFCs, we developed a cost model for tubular SOFC systems. A lack of cost and installed capacity data, however, did not enable us to derive an accurate learning rate for such designs.

\section{Acknowledgements}

This research is funded by the Netherlands Organization for Scientific Research (NWO) under the ACTS Sustainable Hydrogen program (no. 053.61.304).

\section{References}

[1] Christou C, Hadjipaschalis loannis, Poullikkas Andreas. Parametric cost-benefit analysis of Integrated Gasification Combined Cycle technology. $3^{\text {rd }}$ ICCCTF. Sardignia, Italy, 2007.

[2] Wright TP. Factors affecting the cost of airplanes. J Aeronaut Sci 1936;3:122-128.

[3] Joskow PL, Rose NL. The Effects of technological change, experience and environmental regulation on the construction of coal burning generation units. The Rand J. of Economics 1985;16(1): 1-17.

[4] Gruebler A, Nakicenovic N, Victor DG. Dynamics of energy technologies and global change. Energy Policy 1999;27:247-280.

[5] Söderholm P, Sundqvist T. Empirical challenges in the use of learning curves for assessing the economic prospects of renewable energy technologies. Ren. Energy 2007;32: 2559-2578.

[6] Schoots K, Ferioli F, Kramer GJ, van der Zwaan BCC. Learning Curves for Hydrogen Production Technology: an assessment of observed cost reductions. International Journal of Hydrogen Energy 2008;33: 2630-2645.

[7] Ferioli F, Schoots K, van der Zwaan BBC. Component-learning for energy technologies: the case of hydrogen production 2008

[8] Schoots K, Kramer GJ, van der Zwaan BCC. Technology Learning for Fuel Cells: an assessment of past and potential cost reductions. Energy Policy 2010; doi:10.1016/j.enpol.2010.01.022.

[9] Molin S, Gazda M, Kusz B, Jasinski P. Evaluation of $316 \mathrm{~L}$ porous stainless steel for SOFC support. Journal of the European Ceramic Society 2009;29(4): 757-762. 
[10] Molin S, Kusz B, Gazda M, Jasinski P. Evaluation of porous 430L stainless steel for SOFC operation at intermediate temperatures. Journal of Power Sources 2008;181(1): 31-37.

[11] Smeacetto F, Salvo M, Ferraris M, Cho J, Boccaccini AR. Glass-ceramic seal to join Crofer 22 APU alloy to YSZ ceramic in planar SOFCs. Journal of the European Ceramic Society 2008;28(1): 61-68.

[12] Fontana S, Chevalier S, Caboche G. Metallic interconnects for solid oxide fuel cell: Effect of water vapour on oxidation resistance of differently coated alloys. Journal of Power Sources doi:10.1016/j.jpowsour.2008.11.041.

[13] Woodward HK. A performance based, multi-process cost model for solid oxide fuel cells.Worcester Polytechnic Inst. 2003.

[14] van Tuel M. SOFC development at ECN. Internal communication. Netherlands, December 2008.

[15] Bucheli O, Zähringer T, Bertoldi M, Herle J, Diethelm S. Customer-Oriented Design, Manufacturing and Thermal Integration of SOFC Stacks at SOFC power Srl. Lucerne Fuel Cell Forum 2008.

[16] Siewers EJ. Process Development for high volume SOFC component production. Energieonderzoek Centrum Nederlands. Confidential report. 2000.

[17] Martinez K, Nguyen T, Ihejiawu C, Diven J, Daugherty E, Treece J, Soyebo L, Ihejiawu C. Fuel Cells for Stationary Power Generation: A Comprehensive Analysis of Technology, Plant Construction, and Marketing Strategy for Small Buildings. The University of Oklahoma. Fuel Cell Corporation. 2004.

[18] International Average Salary Income Database. Worldsalaries 2008. See: http://www.worldsalaries.orgl (September 2009).

[19] Christiansen N, Hansen JB, Kristensen S, Holm-Larsen H, Linderoth S, Hendriksen PV, Larsen PH, Mogensen P. SOFC Development Program at Haldor Topsøe/Ris $\varnothing$ Laboratory - Progress. FuelCell Forum 2008.

[20] Christiansen N, Hansen JB, Holm-Larsen H, Jørgensen MJ, Kuhn TL, Hendriksen PV, Hagen A, Linderoth S. Solid Oxide Fuel Cell Research and Development at Tops $\varnothing$ Fuel Cell A/S and Risø/DTU. Fuel Cell Forum 2008.

[21] Holm-Larsen H, Andersen CV, Jacobsen J, Primdahl S, Jørgensen MJ, Christiansen N. SOFC for m-CHP, APU and Distributed Generation-Application-Driven Development, Testing and Manufacture. Fuel Cell Forum 2008.

[22] Huiberts R, Buchner KH, Baldus HP. Commercialisation of SOFC Technology at H.C. Starck. FuelCell Forum 2008.

[23] Arthur D.Little Inc. Conceptual design of POX/ SOFC 5kW net system. Final Report. DoE - NREL. USA. January 2001. 